\title{
DIVERSIDAD DE MARIPOSAS DIURNAS (INSECTA: LEPIDÓPTERA) DE UN BOSQUE SUBANDINO, CAJIBÍO, CAUCA*
}

\author{
Diana Marcela Vélez Lemos ${ }^{I}$ María Cristina Gallego-Ropero2², Yilton Riascos Forero ${ }^{3}$
}

\section{Resumen}

En el departamento del Cauca aún persisten algunos pequeños fragmentos de bosque subandino. La reserva natural "Raíces de Vida", colegio Carmen de Quintana (Cajibío, Cauca), cuenta con uno de estos fragmentos pero se encuentra influenciado por zonas con propósitos agropecuarios, lo cual hizo urgente la necesidad de investigar su estado para implementar a tiempo estrategias educativas, que ayuden a tomar decisiones en cuanto a su manejo, con este objetivo se realizó un muestreo de la comunidad de lepidópteros diurnos para ser utilizado como parámetro biológico. Con los datos obtenidos de la riqueza y abundancia de los lepidópteros, se realizó un análisis de cómo esta comunidad se encuentra asociada al estado del bosque. Se registró un total de 785 mariposas, distribuidas en 80 especies, pertenecientes a la superfamilia Papilionioidea y representadas por cuatro familias Pieridae, Hesperiidae, Nymphalidae y Lycaenidae. En total se encontraron 14 especies indicadoras de ecosistemas perturbados, entre ellas Leptophobia aripa, Anartia amathea, Euptychia hermes y Phoebis sennae, y del buen estado del bosque especies como Manataria maculata, Pseudohaetera hypaesia, Taygetis chrysogone, Memphis lyceus y Heliconius erato chestertoni. Estos resultados permiten sugerir que este fragmento de bosque se encuentra en un estado sucesional intermedio, lo que hace de este un espacio importante de conservación y educación ambiental.

Palabras clave: sucesión, conservación, antropización.

\section{DIVERSITY OF DIURNAL BUTTERFLIES OF SUB-ANDEAN FOREST, CAJIBÍO, CAUCA}

\begin{abstract}
In the department of Cauca, still remains small fragments sub-Andean forest persist. The nature reserve "Raíces de Vida" (Roots of Life) of the school "Carmen Quintana", at Cajibío (Cauca), has one of these fragments but influenced by areas of agricultural uses. This prompted a need for investigate the actual state in order to define and, if needed, implement educational and management strategies. With this objective in mind, a sampling of diurnal Lepidoptera community (as a biological indicator) was carried out. Analyses of data of richness and abundance of Lepidoptera allowed to defined how this insect community is associated with

\footnotetext{
${ }^{*}$ FR: 28-IV-2014 . FA: 3-III-2015.

${ }^{1}$ Bióloga. E-mail: moneco84@gmail.com

${ }^{2}$ Ph.D. Profesora Departamento de Biología, Universidad del Cauca. Popayán, Colombia. E-mail: mgallego@unicauca.edu.co. Autor para correspondencia.

${ }^{3}$ Ph.D. Profesor Departamento de Matemática, Universidad del Cauca. Popayán, Colombia. 
the state of the forest. A total of 785 butterflies, grouped in 80 species, was recorded. Specimens belong to the superfamily Papilionioidea and represent four families: Pieridae, Hesperiidae, Nymphalidae and Lycaenidae. A total of 14 species, indicators of disturbed ecosystems, include Leptophobia aripa, Anartia amathea, Euptychia hermes and Phoebis sennae. On the other hand, a good forest species like Manataria maculata, Pseudohaetera hypaesia, Taygetis chrysogone, Memphis lyceus and Heliconius erato chestertoni were found. Results suggest that this small forest fragment is under an intermediate successional stage, hence representing an important area for conservation and environmental education strategies.

Key words: succession, conservation, anthropization.

\section{INTRODUCCIÓN}

Cajibío es un municipio con gran actividad agrícola donde predominan los cultivos de flores, pinos, eucaliptos y espárragos; monocultivos que en su proceso empobrecen el suelo y, por ende, disminuyen la poca vegetación circundante (RAMÍREZ et al., 2006). Estas actividades antrópicas en la región tienen como consecuencia un proceso de degradación paulatina que produce la separación de masas arbóreas por carreteras, caminos y fincas, actividades que progresivamente afectan la riqueza biológica del territorio.

Las mariposas son insectos de gran importancia en los ecosistemas por las funciones ecológicas que cumplen (BROWN, 1997). Además, son consideradas como un grupo indicador confiable para estudios de inventario o monitoreo de biodiversidad, conservación y endemismos, debido a su sensibilidad a los cambios de temperatura, humedad, radiación solar y disminución de plantas hospederas y alimenticias (KREMEN et al., 1993; KREMEN, 1994), características que las convierte en una herramienta importante para hacer predicciones y/o evaluar el grado de intervención o conservación en el que se encuentra un ecosistema, y poder así diseñar estrategias a través de programas de conservación que mitiguen el impacto generado por las diferentes actividades antrópicas.

La reserva natural "Raíces de Vida" cuenta con 17 ha, y un buen porcentaje, incluyendo las áreas aledañas, están influenciadas por zonas con propósitos agropecuarios, por lo tanto, el presente estudio determinó la diversidad y abundancia de la comunidad de mariposas diurnas como parámetro biológico para poder evaluar los problemas ambientales que presenta y conocer el grado de antropización en que se encuentra.

\section{MATERIALES Y MÉTODOS}

\section{Área de estudio}

La reserva natural "Raíces de Vida" ( $2^{\circ} 27^{\prime} \mathrm{N}-78^{\circ} 34^{\prime}$ W) se localiza en el municipio de Cajibío a una altura de $1765 \mathrm{msnm}$. Este municipio posee una extensión de 
$747 \mathrm{~km}^{2}$ y se encuentra al noroccidente del departamento del Cauca a $28 \mathrm{~km}$ de la ciudad de Popayán. Parte del territorio es montañoso y su relieve corresponde a las vertientes oriental y occidental de las cordilleras Central y Occidental. Limita por el norte con los municipios de Morales y Piendamó, y por el oriente con Popayán y El Tambo (Figura 1).

El sistema hidrográfico del municipio está conformado por tres grandes cuencas: río Piendamó-Cajibío, río Palacé-Robles y río Sucio-Ortega. Entre los principales ríos están: Cofre, Cauca, Dinde, Palacé, La Pedregosa, Cajibío, Ortega y Guanguillo (RAMÍREZ et al., 2006).

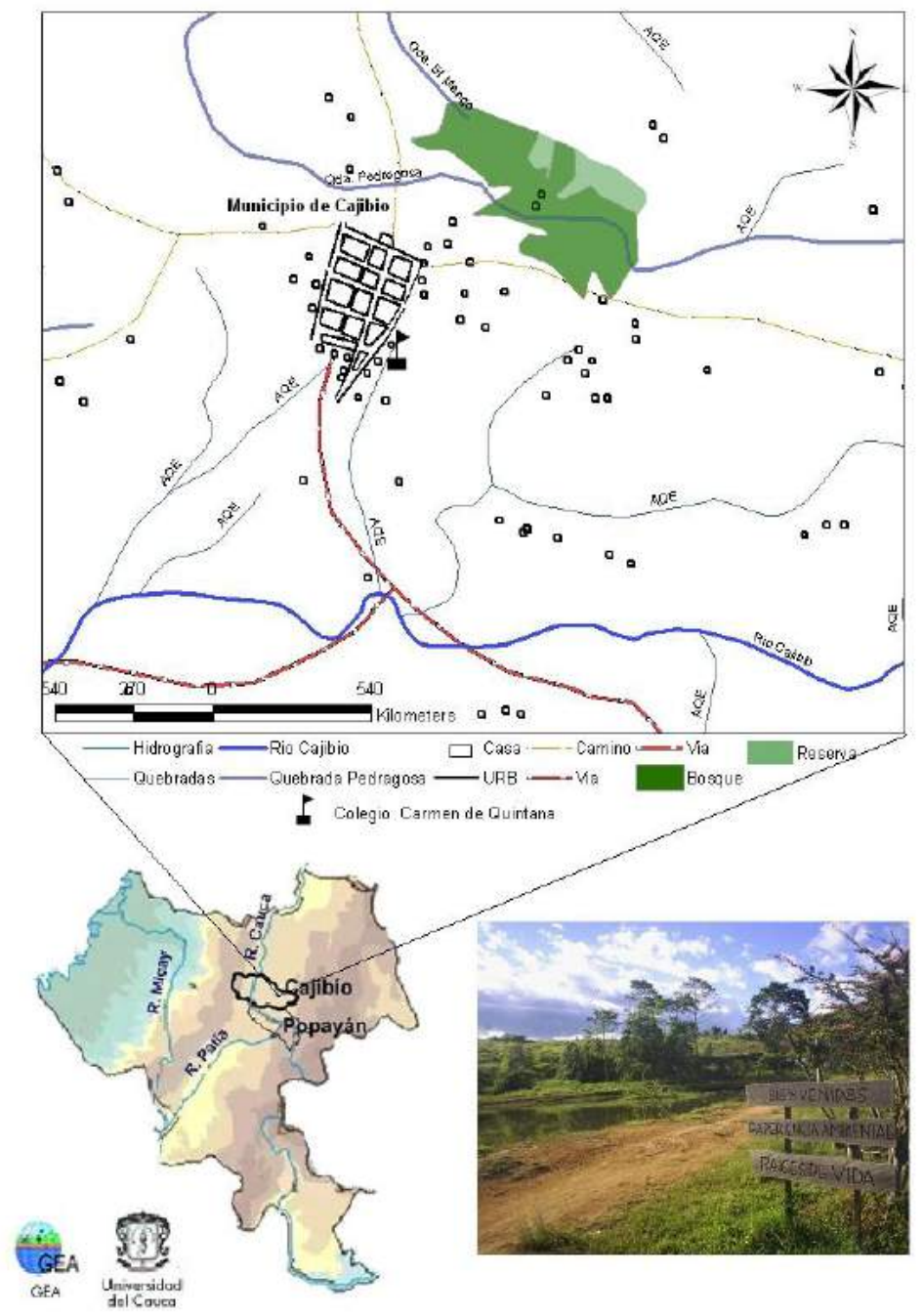

Figura 1. Localización geográfica de la reserva natural "Raíces de Vida”, colegio Carmen de Quintana (Cajibío, Cauca). 


\section{MÉTODOS DE MUESTREO}

\section{Muestreo de lepidópteros}

Se trazaron tres transectos de 250 metros de longitud, separados 200 metros entre sí. En cada transecto se instalaron 6 trampas Van Someren-Rydon (Figura 2) (RYDON 1964), separadas 50 metros entre sí y a 50 metros del margen del bosque para evitar el efecto de borde, y a una altura de 1 a 3 metros del suelo. Las trampas fueron cebadas con banano fermentado y se dejaron durante tres días, siendo revisadas cada tres horas entre las 8:00 a.m. y las 5:00 p.m.

El muestreo se complementó capturando ejemplares con jama entomológica por los transectos, en los intervalos de tiempo entre la revisión de las trampas durante el día, teniendo en cuenta el mismo esfuerzo de muestreo de dos horas jameo/día/ transecto (324 horas). Es de aclarar que se hizo una primera colecta de los individuos y con ellos se elaboró una cartilla de campo con los morfotipos de las mariposas que facilitó la identificación en campo y, además, evitó una alta mortalidad de individuos. El material colectado fue debidamente montado e identificado en el laboratorio. La colección de especímenes se depositó en el Museo de Historia Natural de la Universidad del Cauca (MHNUC).

\section{Caracterización habitacional del relicto de bosque de la reserva natural "Raíces de Vida"}

Para realizar la caracterización habitacional de la reserva, se trazaron tres transectos lineales de 250 metros de longitud, separados el uno del otro al menos 200 metros y se midieron cinco variables habitacionales que pueden influir en la presencia y actividad de los lepidópteros, a saber: cobertura de dosel (medido con un densímetro esférico Forestry Suppliers), espesor y volumen de hojarasca, DAP de los árboles, altura estimada, y se colectaron muestras de los árboles con perímetro superior a $25 \mathrm{~cm}(8,13 \mathrm{~cm}$ diámetro a la altura del pecho o DAP) con el fin de estimar la riqueza y densidad arbórea por unidad de área.

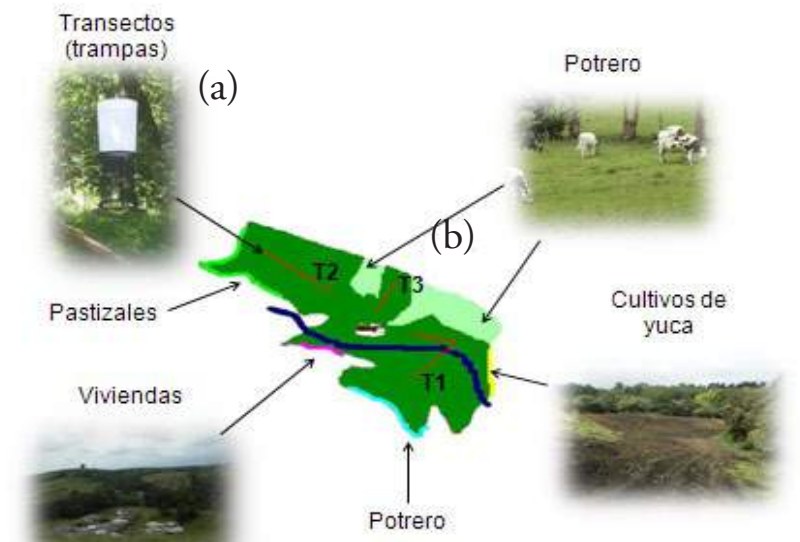

Figura 2. (a) Instalación de trampas Van Someren-Rydon. (b) Esquema de ubicación de los transectos dentro del relicto de bosque y delimitación de usos del suelo de la matriz aledańa. 


\section{Evaluación ecológica rápida}

Para realizar la evaluación ecológica rápida se empleó el método de matrices de interacción conocido como la matriz de FEARO, y posteriormente las fichas de manejo ambiental.

Matriz de FEARO. En esta matriz se relaciona una lista de actividades antrópicas que pueden estar afectando el sistema; al finalizar este proceso, se puede determinar si es necesario realizar un estudio exhaustivo de impacto ambiental, teniendo como ventaja la información reunida, la cual servirá para definir las áreas que requieren especial atención (FIGUEROA et al., 1998). Para diligenciar la matriz se obtuvo información no solo de observaciones directas, sino también de la suministrada por los moradores del lugar.

Ficha de manejo ambiental. Con la información recopilada en la matriz de FEARO, se generó la ficha de manejo ambiental, la cual contiene las actividades mitigadoras de las acciones tensoras identificadas en el relicto de bosque.

\section{Análisis de los datos}

Los datos de riqueza y abundancia relativa de especies, fueron analizados usando el programa EstimateS 5.1 (COLWELL, 1998) y se calcularon los índices de Shannon $\left(\mathrm{H}^{\prime}\right)$ y dominancia de Simpson, asimismo se elaboraron las curvas de acumulación de especies para establecer la eficiencia del muestreo. Se emplearon estimadores basados en la incidencia (presencia-ausencia), porque son los más apropiados en el análisis de grupos hiperdiversos y con distribuciones agrupadas (LONGINO, 1994), como Chao 2 e ICE. Se realizaron correlaciones entre las variables de vegetación y ambientales medidas con la riqueza y abundancia de lepidópteros.

\section{RESULTADOS}

Un total de 785 mariposas diurnas fueron registradas, distribuidas en 80 especies (Tabla 1), pertenecientes a la superfamilia Papilionioidea, las cuales están representadas por cuatro familias: Pieridae, Hesperiidae, Nymphalidae y Lycaenidae. Nymphalidae fue la familia más abundante con 735 individuos (Figura 3). Lo cual es bastante congruente con los trabajos de ANDRADE (1993a, 1993b) en Ucumarí (Risaralda), SALAZAR (1995) en Putumayo, FAGUA (1996) en la Serranía del Taraira (Vaupés), PRIETO \& CONSTANTINO (1996) en el valle del río Tatabro (Valle del Cauca), ARIAS \& HUERTAS (2001) en la Serranía de los Churumbelos (Cauca), RODRÍGUEZ \& RAMÍREZ (2004) en el departamento del Quindío, FRAIJA \& FAJARDO (2005) en los Llanos Orientales colombianos y GÓMEZ (2006) en la reserva natural del Ocaso en el Quindío.

Las subfamilias más representativas fueron Satyrinae e Ithomiinae con 450 y 102 individuos, respectivamente. La persistencia de mariposas Ithomiinae, según BROWN \& FREITAS (2002) en un estudio realizado sobre la comunidad de mariposas en varios fragmentos de bosque urbanos en la ciudad de Campinas (Brasil), garantiza la formación de "bolsillos" de humedad en parques arbolados y con buena fuente de agua. En el área del presente estudio se observó gran abundancia de ithomiinos, posiblemente obedeció a que por esta zona pasa una quebrada llamada La Pedregosa, la cual se mantiene con caudal la mayor parte del año. RAMÍREZ (2004) 
en su estudio sobre la diversidad de especies de mariposas asociadas a diferentes ecoparques en la ciudad de Cali, confirma en sus resultados que Ithomiinae presentó una reducción en la riqueza específica a medida que disminuían las fuentes de agua, por ejemplo en el Ecoparque Lago de las Garzas se presentaron tres especies mientras que 12 en el río Pance, contrastando notoriamente con el Ecoparque Bataclán sin fuentes de agua y que no registró ninguna especie de esta subfamilia.
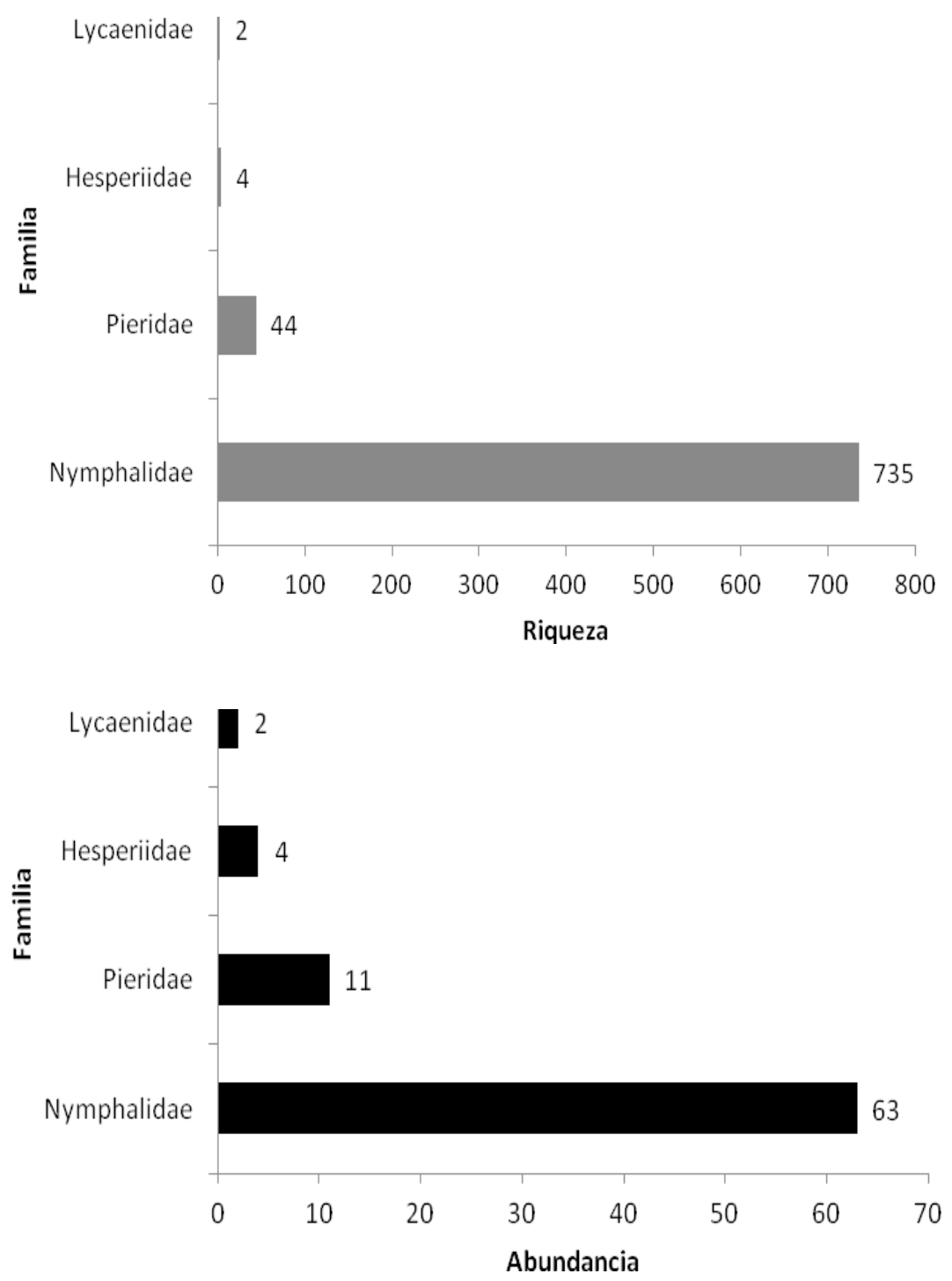

Figura 3. Riqueza (N: 80) y abundancia (N: 785) de especies de mariposas por familia colectadas en la reserva natural "Raíces de Vida”, colegio Carmen de Quintana (Cajibío, Cauca). 
Tabla 1. Riqueza de especies de lepidópteros (Rophalocera) de la reserva natural "Raíces de Vida", colegio Carmen de Quintana (Cajibío, Cauca).

FAMILIA/SUBFAMILIA

ESPECIE

\section{NYMPHALIDAE}

\section{Ithomiinae}

Greta andromica

Mechanitis sp. 1

Miraleria cymothoe

Oleria makrena makrena

Pteronymia veia

Ithomiinae sp.2

Ithomiinae sp. 3

\begin{tabular}{ll}
\hline Heliconiinae & Heliconius clysonymus \\
& Heliconius erato chestertoni \\
& Heliconius cydno weymeri \\
& Heliconius cydno submarginatus \\
& Heliconius sp.5 \\
& Heliconius sp.6 \\
\hline Brassolinae & Caligo memnon \\
& Caligo prometheus \\
& Caligo sp.2 \\
\hline Acraeinae & Actinote equatoria \\
& Actinote ozomene \\
& Actinote anteas \\
& Actinote stratonice \\
& Archaeoprepona amphimachus \\
& Archaeoprepona demophon \\
& Archaeoprepona demophon muson \\
Archaeoprepona sp.2 \\
Memphis lyceus \\
Memphis morvus morpheus \\
Memphis pseudiphis \\
Adelpha alala \\
Adelpha lycorias \\
Adelpha leucophthalma \\
Anartia amathea \\
Catonephele chromis \\
Catonephele numilia esite \\
\hline Nymphalinae
\end{tabular}




\section{FAMILIA/SUBFAMILIA}

\section{ESPECIE}

Colobura dirce

Diaethria marchalii

Ephiphile epimenes kalbreyeri

Nymphalinae sp.1

Siproeta epapus

\begin{tabular}{ll}
\hline Melitaeinae & Castilia eranites \\
& Castilia sp.1 \\
& Chlosyne locinia \\
\hline Tegosa anieta \\
\hline Eutyrinae & Euptychoides saturnus \\
& Euptychia polyphemus \\
& Hermeuptychia hermes \\
& Magneutychia alcinoe \\
& Manataria maculata \\
& Oressinoma typhla \\
& Pseudohaetera hypaesia \\
& Pareuptychia metaleuca \\
& Parataygetis lineata \\
& Pronophila brennus \\
& Pronophila orcus \\
& Taygetis andromeda \\
& Taygetis chrysogone \\
Satyrinae sp.1 & Pseudomaniola pholoe \\
Lycorea cleobaea \\
Catasticta flisa \\
Leodonta dysoni \\
Leodonta tellane intermedia \\
Hesperiidae sp.1 \\
Astraptes fulgerator \\
Urbanus teleus \\
Urbanus sp.1 \\
\hline DESPERIIDAE \\
\hline Danainae
\end{tabular}

\section{PIERIDAE}

Pierinae

Leptophobia aripa

Pierinae sp. 1 


\begin{tabular}{ll}
\hline FAMILIA/SUBFAMILIA & ESPECIE \\
\hline Dismorphinae & Dismorphia crisia foedora \\
& Dismorphia zathoe othoe \\
& Dismorphia mirandola discolera \\
& Dismorphia medora \\
\hline Coliadinae & Eurema albula \\
& Eurema daira lydia \\
& Eurema proterpia \\
& Eurema venusta \\
& Eurema xanthochlora \\
& Phoebis sennae marcellina \\
\hline LYCAENIDAE & \\
Riodininae & Euselasia eupatra \\
& Leucochimona philemon \\
\hline
\end{tabular}

La familia con mayor riqueza registrada fue Nymphalidae con 63 especies, agrupadas en 9 subfamilias, de las cuales Satyrinae y Nymphalinae obtuvieron los valores más altos de riqueza específica con 15 y 11 spp., seguidos por Ithomiinae con siete especies (Figura 4). BROWN \& FREITAS (2002) afirman que entre las mariposas las mejores supervivientes de las diferentes alteraciones a los ecosistemas pertenecen a las subfamilias Nymphalinae e Ithomiinae. Pieridae estuvo representada por nueve especies y dos subfamilias, Hesperiidae con cuatro especies y Lycaenidae con tan solo dos especies de la subfamilia Riodininae, lo que sugiere la existencia de poblaciones muy pequeñas y localizadas, o un sesgo en su captura probablemente debido a sus coloraciones opacas, tamaños relativamente pequeños y vuelo particularmente rápido (RAMÍREZ, 2004).

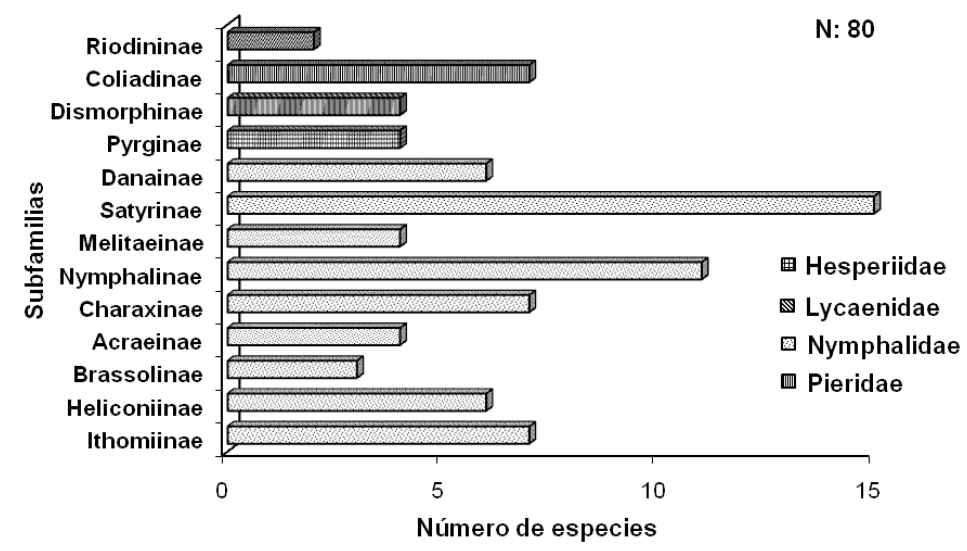

Figura 3. Riqueza de especies de mariposas distribuidas por subfamilia colectadas en la reserva natural "Raíces de Vida", colegio Carmen de Quintana (Cajibío, Cauca). 


\section{Curvas de acumulación de especies y estimadores de riqueza}

La Figura 5 refleja el comportamiento de captura de mariposas en la reserva. Al graficar los estimadores ICE y Chao 2 (112,83 y 99,31, respectivamente) y la riqueza observada, se genera una curva tendiente a la asíntota. Al calcular con base en los estimadores la eficiencia de muestreo, se obtiene un valor de $75,42 \%$. De todas maneras, es posible que al aumentar el tiempo y esfuerzo de muestreo, se logre incrementar la riqueza con nuevas especies en la reserva.

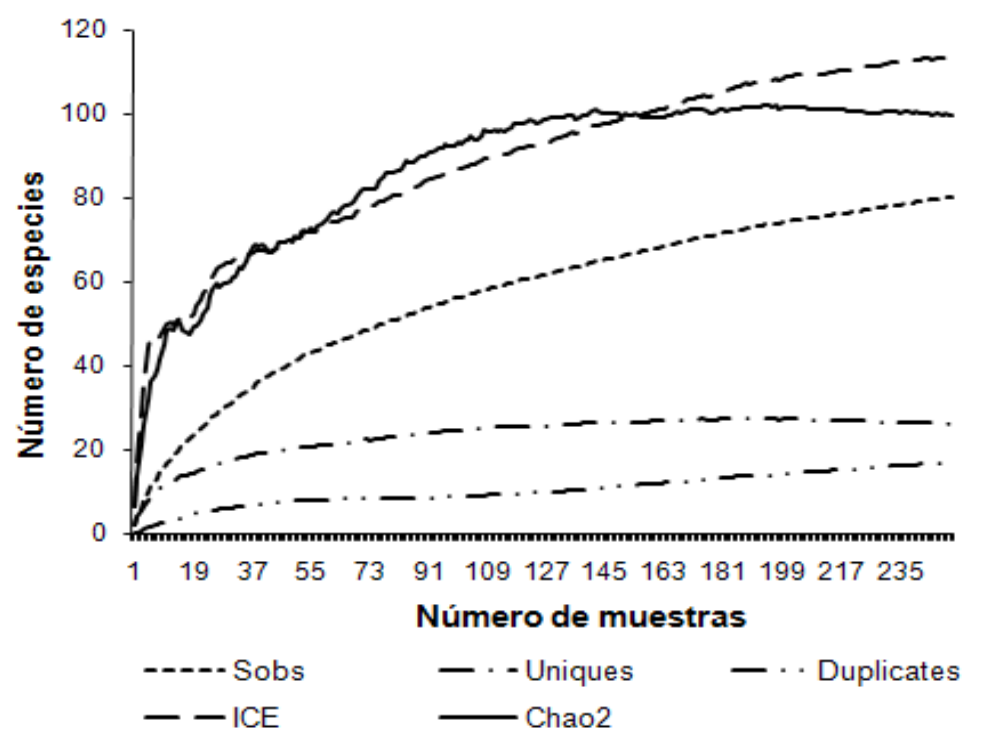

Figura 5. Curva de acumulación de especies.

Probablemente el valor que sugieren los estimadores pudo estar influenciado por las fuertes precipitaciones presentadas en los dos últimos muestreos (Figura 6). La lluvia y la nubosidad constantes son variables que disminuyen la actividad de vuelo e influyen en el comportamiento de los lepidópteros (PALACIOS, 2006). Una tendencia similar registran TOBAR et al. (2002) en la diversidad de mariposas encontrada en la parte alta de la cuenca del río El Roble (Quindío), donde de las 203 especies observadas, en la época lluviosa se registraron 144 y en la seca se registraron 172 especies, concluyendo que en general los mayores valores de riqueza y abundancia de especies se presentaron durante la época seca. Se resalta que para las condiciones ambientales del área de estudio, la riqueza y abundancia permanecían similares, en un rango de temperatura entre 18 y 19 grados, pero a lo largo de los muestreos se evidenció que el cambio de ese rango de temperatura, influyó notoriamente en el valor de la riqueza y abundancia de mariposas, es por esto que, como se observa en la Figura 6a, la tendencia entre las dos variables es directamente proporcional, al aumentar la temperatura aumenta la riqueza y abundancia y viceversa (Coeficiente de correlación 0,68 y 0,75, respectivamente). 
En la Figura 6b se puede observar el comportamiento inversamente proporcional que se presenta con la variable precipitación, en donde las fuertes lluvias disminuyeron la riqueza y abundancia de los lepidópteros (Coeficiente de correlación - 0,77 y - 0,85 , respectivamente).
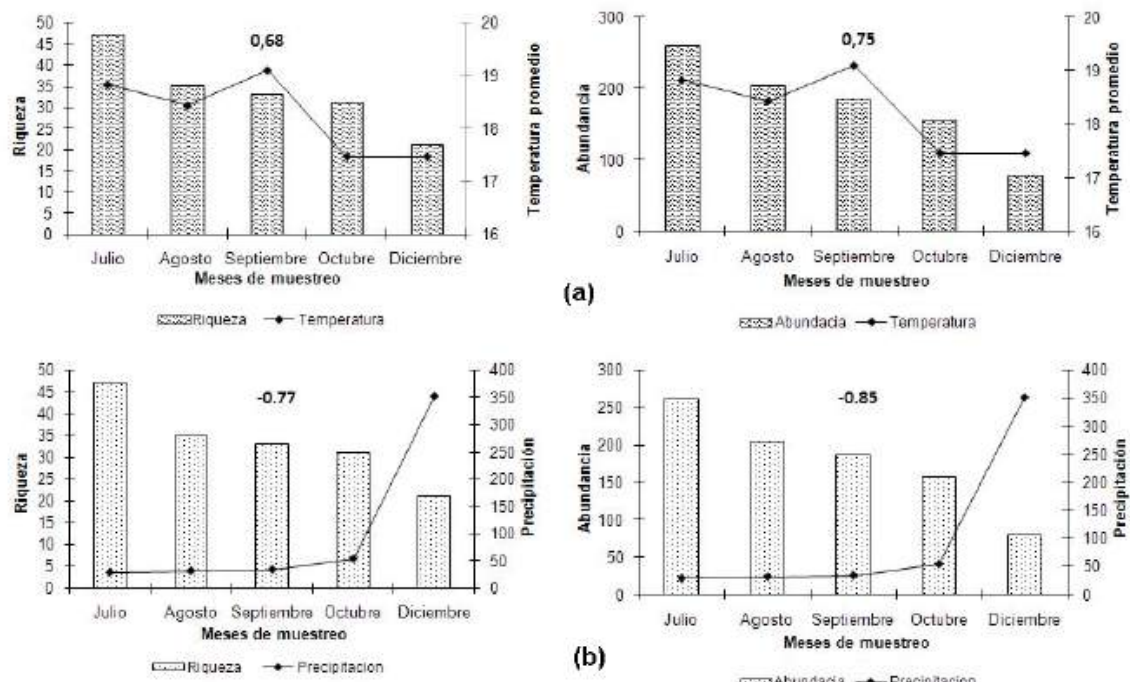

Figura 6. Riqueza y abundancia de especies vs (a) temperatura; (b) precipitación.

\section{Caracterización habitacional del fragmento de bosque de la reserva}

Dentro de las 17 ha que corresponden al fragmento de bosque que hace parte de la reserva en estudio, se pueden diferenciar cuatro estratos: arbóreo, arbóreo superior, arbustivo y herbáceo, de los cuales prevalece el estrato arbustivo. Según la caracterización florística realizada en la reserva (RAMÍREZ et al., 2006), se pudo concluir que el bosque presenta una notoria intervención antrópica, pues los valores bajos de DAP y altura pertenecientes a especies vegetales que se caracterizan por su gran tamaño y grosor, indicaron que el bosque se encuentra en un proceso sucesional temprano. También, por medio del inventario general, se encontraron especies de crecimiento rápido que se catalogan como especies de bosque secundario como por ejemplo Heliocarpus americanus y Cecropia angustifolia, que ratificaron el impacto que ejercen las actividades que realizan los habitantes del sector.

Los árboles presentes son pocos y no muestran dimensiones apreciables en altura y en grosor. Escasamente alcanzan los $20 \mathrm{~m}$ de altura y raramente sobrepasan las circunferencias mayores a $1 \mathrm{~m}$. En el estrato arbustivo es notoria la presencia de juveniles pertenecientes a los estratos superiores; esto es característico de los bosques en sucesión y es una garantía para la conservación del área boscosa, ya que existen elementos que crecerán y formarán el dosel posteriormente (RAMÍREZ et al., 2006). 
En el interior de la reserva se encuentran zonas más despejadas o abiertas (claros) que otras, se podría plantear que en las áreas que se trazaron los transectos para el muestreo, se observa un grado diferente de intervención (Figura 2b). Por ejemplo, en el transecto uno, se encuentra el sendero ecológico que permite el fácil acceso de personas, a su alrededor se encuentran cultivos de yuca, pequeñas áreas cultivadas con café y predomina también la ganadería. El área donde se ubicó el transecto dos, es un poco más pequeña que la del transecto uno y a pesar de que se nota perturbado por el ingreso de personas que talan, pastoreo accidental del ganado y muy cercano a la construcción de viviendas, se aprecia notoriamente más conservado que éste, incluso los porcentajes de cobertura vegetal medidos difieren (Figura 7). El transecto tres, siendo el de área más reducida, es el que en mejor estado se observa, aquí se encuentra el nacimiento de agua y la Institución se preocupa por su protección y conservación, incluso los cultivos que tiene el colegio con los estudiantes alrededor son manejados sin aplicación de insumos químicos, en este transecto no se observan claros ni actividades muy cercanas de ganadería; en esta área se presenta el mayor porcentaje de cobertura vegetal. La Figura 7e, muestra el comportamiento inversamente proporcional de la riqueza y abundancia de mariposas con el porcentaje de cobertura vegetal (Coeficiente de correlación de -0,99).
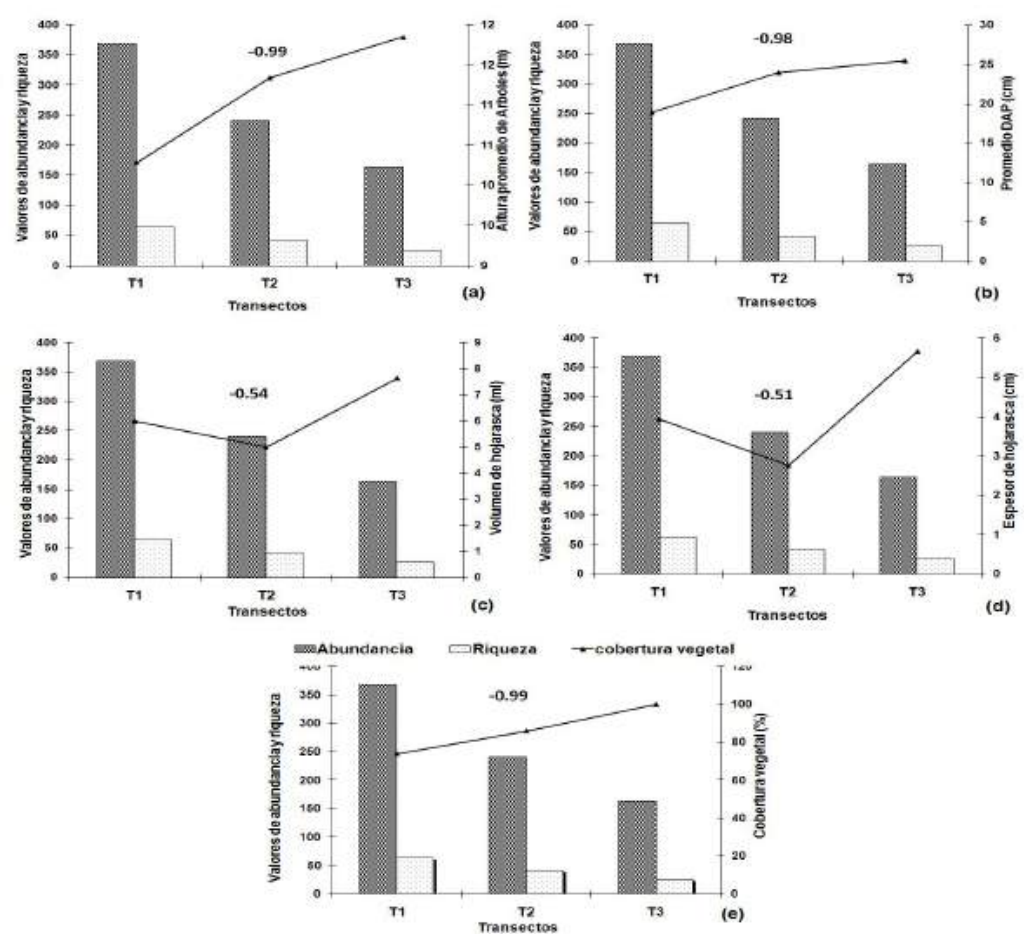

Figura 7. Variables habitacionales vs riqueza y abundancia de especies de lepidópteros para los tres transectos en la reserva natural "Raíces de Vida”, colegio Carmen de Quintana (Cajibío, Cauca). 
Teniendo en cuenta lo anterior, los resultados presentan la mayor riqueza y abundancia de especies de mariposas en el área donde se ubicó el transecto uno con 67 especies y 373 individuos. Se debe aclarar que la presencia de espacios abiertos facilitó el uso de la jama entomológica, y la presencia de excretas de ganado vacuno se constituyó en una fuente adicional de nutrientes orgánicos para los lepidópteros; a la vez, estos claros permiten el incremento de la luminosidad, beneficiando así procesos vitales para las mariposas como la termorregulación y el florecimiento de algunas especies vegetales fuente de néctar (PRIETO \& CONSTANTINO, 1996).

Por otro lado, POLLARD \& YATES (1996) mencionan que los altos niveles de sombra afectan negativamente la abundancia de mariposas, pues son animales que necesitan cierto nivel de insolación para volar. Señalan también, que el grado de insolación de una zona va a condicionar la presencia de flores para que liben los adultos y de plantas nutricias para la alimentación de las larvas. En el interior de las formaciones boscosas el grado de insolación es un factor crítico que gobierna la selección de hábitat de muchas especies, cada una de las cuales puede presentar asociaciones con niveles de sombra específicos (WARREN, 1985). Así, es normal encontrar especies propias de prados en las zonas abiertas (caminos y claros) de los bosques, pues en estos lugares se encuentran hábitats adecuados intercalados entre el dosel arbóreo (JIMÉNEZ et al., 2004).

La aparente mayor diversidad presente en el transecto uno que se encuentran con mayor grado de perturbación, se explica al indicar que dichas especies han sido reportadas por mostrar preferencia por zonas o espacios abiertos; en la reserva natural "Raíces de Vida" se registraron 226 individuos de 14 especies indicadoras de áreas perturbadas y tan solo 64 individuos de cinco especies indicadoras del estado de conservación del relicto de bosque.

Por ejemplo, en los transectos uno y dos se encontró Heliconius erato, una especie característica de áreas poco intervenidas y típica de bosques secundarios; lo cual contrasta con la presencia de Anartia amathea, Euptychia hermes y Phoebis sennae, especies que se han registrado como indicadoras de ecosistemas con un alto grado de intervención (ANDRADE, 1994). Estos datos concuerdan con los reportados en el Tolima acerca de Euptychia hermes indicadora de hábitats abiertos (Figura 8) (GARCÍA et al., 2007). Además, de acuerdo con ANDRADE (2002), el aumento de las áreas agrícolas induce el establecimiento de algunas especies de mariposas propias de zonas de cultivos tales como Leptophobia aripa y la colonización de otras áreas urbanas y suburbanas por la introducción de plantas de ornato, es típico encontrar mariposas como Anartia amathea.

En el estudio realizado por TOBAR et al. (2002) se registraron especies de áreas abiertas, donde la estructura del área muestreada es más sencilla y la influencia de los factores ambientales es más fuerte. Algunas de estas especies también se observaron en la reserva como: Anarthia amathea, Actinote equatoria, Adelpha alala, Heliconius clysonimus, Diaethria marchalii, Eurema venusta, E. xanthochlora y Oxeoschistus simplex. 


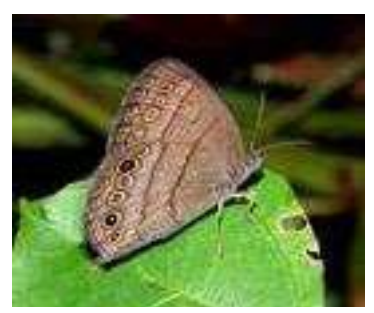

Figura 8. Euptychia hermes, especie típica de áreas perturbadas.

\section{Índice de diversidad de Shannon-Wiener y dominancia de Simpson}

Índice de diversidad de Shannon-Wiener. El valor obtenido para este índice fue de 3,22, lo que sugiere una relativa alta diversidad de especies de lepidópteros presentes en la reserva. Este valor de diversidad es alto, comparado con el valor obtenido por GÓMEZ (2006) en su estudio sobre la composición de mariposas en diferentes hábitats de la reserva El Ocaso (Quindío), donde obtuvo un valor para el bosque de 1,68 y para potrero de 2,07, teniendo en cuenta que el área en El Ocaso es mucho mayor con 110 ha.

Sin embargo, investigaciones han mostrado que la riqueza de mariposas disminuye a medida que el grado de urbanización aumenta (BROWN \& FREITAS, 2002), no solo porque la construcción de edificaciones y carreteras reemplaza y/o reduce el área de los hábitats naturales, sino además porque la calidad de los hábitats residuales es afectada por varias formas de polución (HARDY \& DENNIS, 1999). Otro motivo que influye sobre la diversidad evidenciado en parques urbanos de Cali, es que el valor del índice no parece depender de la extensión de la zona verde sino de la heterogeneidad vegetal y la presencia de relictos boscosos (RAMÍREZ, 2004). Según BROWN (1997), la diversidad total de mariposas no disminuye con el área de los fragmentos. Para las mariposas el mundo es un mosaico de parches de luz, calor, compuestos químicos y alimento, y su presencia depende de la combinación de estos y otros factores. La diversidad de especies en los fragmentos está determinada principalmente por la variedad de microhábitats y de recursos como plantas hospederas para las larvas, o flores y frutos para los adultos (RAMÍREZ, 2004).

ANDRADE (2002), en un análisis de la distribución y diversidad de las mariposas de Colombia a partir del estudio de la Colección Entomológica del Instituto de Ciencias Naturales, mostró la fuerte reducción de la riqueza entre los 1500 y los $1800 \mathrm{msnm}$, franja que representa un área de transición entre comunidades de tierras bajas y comunidades típicas de montaña. El 80\% de las especies estudiadas fueron encontradas en la franja de los 300 a los $900 \mathrm{~m}$ de altitud, el $45 \%$ en la franja de 900 a los 1800, y en la franja de los 1800 a los 2700 solo el $10 \%$.

Otro fenómeno directamente asociado con la conservación de las poblaciones, es que con frecuencia las zonas de media y alta montaña son áreas que se utilizan como corredores en las migraciones de las especies de mariposas. También, hay que tener en cuenta los desplazamientos que suceden de las partes bajas hacia las zonas altas, los cuales se deben a la búsqueda de sitios de forrajeo y mejores condiciones climáticas. De la mayoría de las especies que ocurren en las montañas, 
se desconoce casi por completo su estructura poblacional, y se ignoran los aspectos de ecología y biogeografía. En numerosos casos no se sabe cuáles son las plantas hospederas, información que podría dar una explicación de su presencia y distribución geográfica (ANDRADE, 2002).

Índice de dominancia de Simpson. Este índice está fuertemente influenciado por la o las especies que dominan en un ecosistema. De esta manera el valor que registró este índice de 0,91 para la reserva, muestra la dominancia de la especie Euptychoides saturnus con 141 individuos (Figura 9a), seguida están Pareuptychia metaleuca con 127 y Euptychia polyphemus con 87 individuos, todas de la subfamilia Satyrinae y Greta andromica de la subfamilia Ithomiinae con 44 individuos.

En un estudio de diversidad y distribución de mariposas Satyrinae en el Tolima (GARCÍA et al., 2007) y de acuerdo con AMAT et al. (1999), para Colombia se estiman 1182 especies de Nymphalidae, de las cuales 299 especies pertenecen a la subfamilia Nymphalinae, 295 especies a Ithomiinae y 225 a Satyrinae, siendo por lo tanto estas tres subfamilias las más representativas. Para la Cordillera Central la subfamilia Satyrinae es la primera en número de especies, con alrededor de 95 especies (ANDRADE \& AMAT, 1996).

La incidencia de una alta diversidad de Satyrinae, tanto en praderas como en bordes de bosque, puede reflejar que estos hábitats son óptimos para el género Euptychia y más específicamente la especie Euptychia hermes presente en el área de estudio, la cual frecuenta plantas de las familias Asteraceae y Poaceae que se encuentran regularmente en hábitats abiertos y zonas de transición (ÁLVAREZ, 1993), lo que coincide con la descripción de la reserva natural "Raíces de Vida" que se caracteriza por una cobertura vegetal más o menos densa, donde predominan los arbustos y las hierbas (RAMIREZ et al., 2006).

En el estudio de GARCÍA et al. (2007), en la cuenca del río Coello (Tolima), el bosque exhibió parches con diferentes estados de sucesión primaria y secundaria, lo cual probablemente deriva en una alta heterogeneidad en los estratos y posibilita un mayor número de microhábitats para algunas especies como Pseudohaetera hypaesia propia del interior de bosque (ÁLVAREZ, 1993), la cual se colectó también en el área de estudio y se caracteriza por mostrar afinidad con el estrato subarbustivo, donde vuela a la altura del estrato herbáceo y rasante, el cual aprovecha debido a su coloración críptica para pasar desapercibidas junto a la hojarasca en el suelo (Figura 9b).

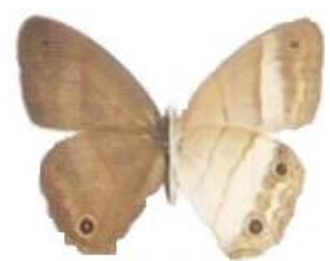

(a)

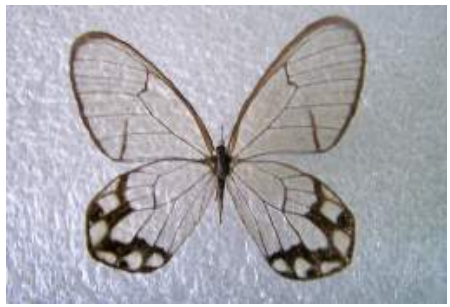

(b)

Figura 7. Euptychoides saturnus (a), especie dominante de la reserva, y Pseudohaetera hypaesia (b), indicadora de interior de bosque. 


\section{Eficiencia de los métodos de muestreo}

En el muestreo realizado con trampas Van Someren-Rydon, se capturaron un total de 422 mariposas pertenecientes a 9 subfamilias de Nymphalidae y 36 especies fueron atraídas a las trampas cebadas con banano fermentado, mostrando ser más efectivas para la captura de mariposas de vuelo alto y rápido, como especies de las subfamilias Charaxinae, Nymphalinae y Satyrinae. Muchos de los adultos de la subfamilia Nymphalinae y el alto número de individuos de la subfamilia Satyrinae se alimentan de materia orgánica como fruta fermentada, excremento y carroña, estas especies además de ser oportunistas, basan su dieta en frutos en descomposición (VÉLEZ \& SALAZAR, 1991). En términos generales, este método fue más efectivo para la abundancia relativa de lepidópteros que para la riqueza (Figura 10a).

En el muestreo con jama entomológica se colectaron 339 individuos con representantes de las cuatro familias: Pieridae, Lycaenidae, Heperiidae y Nymphalidae distribuidas en 13 subfamilias y 67 especies, entre ellas las más abundantes en la colecta fueron Ithomiinae y Satyrinae con 96 mariposas cada una. Nymphalidae fue la familia con mayor riqueza de especies, donde las subfamilias más significativas fueron Satyrinae con 14 y Nymphalinae con nueve especies (Figura 10b), y al menos se capturó una especie para cada subfamilia. La abundancia fue menor para el muestreo realizado con jama, tal vez haya sido afectado por la utilización de jamas cortas, limitando la eficacia en la captura de mariposas, lo cual podría explicar la diferencia en número de individuos que se presentó con la captura en trampas Van Someren-Rydon.

Otra razón por la que pudo ser más efectiva la captura de especies con jama entomológica, es que las mariposas dependiendo de la familia o hasta en algunos géneros, eligen ambientes muy distintos, a unas les agrada sitios donde haya entradas de luz u otras adaptadas a condiciones de sombra, zonas más despejadas para su parcheo, o unas que descansan sobre las hojas o alimentándose de excrementos de pájaros, atraídas por los olores de las flores o al lado de charcos y ríos chupando la humedad de la arena (BROWN \& FREITAS, 2002). Todas estas preferencias probablemente hacen de la jama un método más selectivo.

Para GÓMEZ (2006), la mayor efectividad en cuanto a riqueza fue la colecta con el método de jameo, el cual superó considerablemente el muestreo con trampas, en parte pudo ser explicado porque no todas las especies son atraídas a los cebos y menos aún si se utilizó solo un tipo de cebo (elaborado a base de banano y cerveza). Sin embargo, con las trampas se lograron colectar especies que tienden a desplazarse a nivel de dosel como es el caso de algunos Charaxinae difíciles de atrapar con jama. De lo anterior, se puede afirmar que estos métodos de colecta se complementan. 

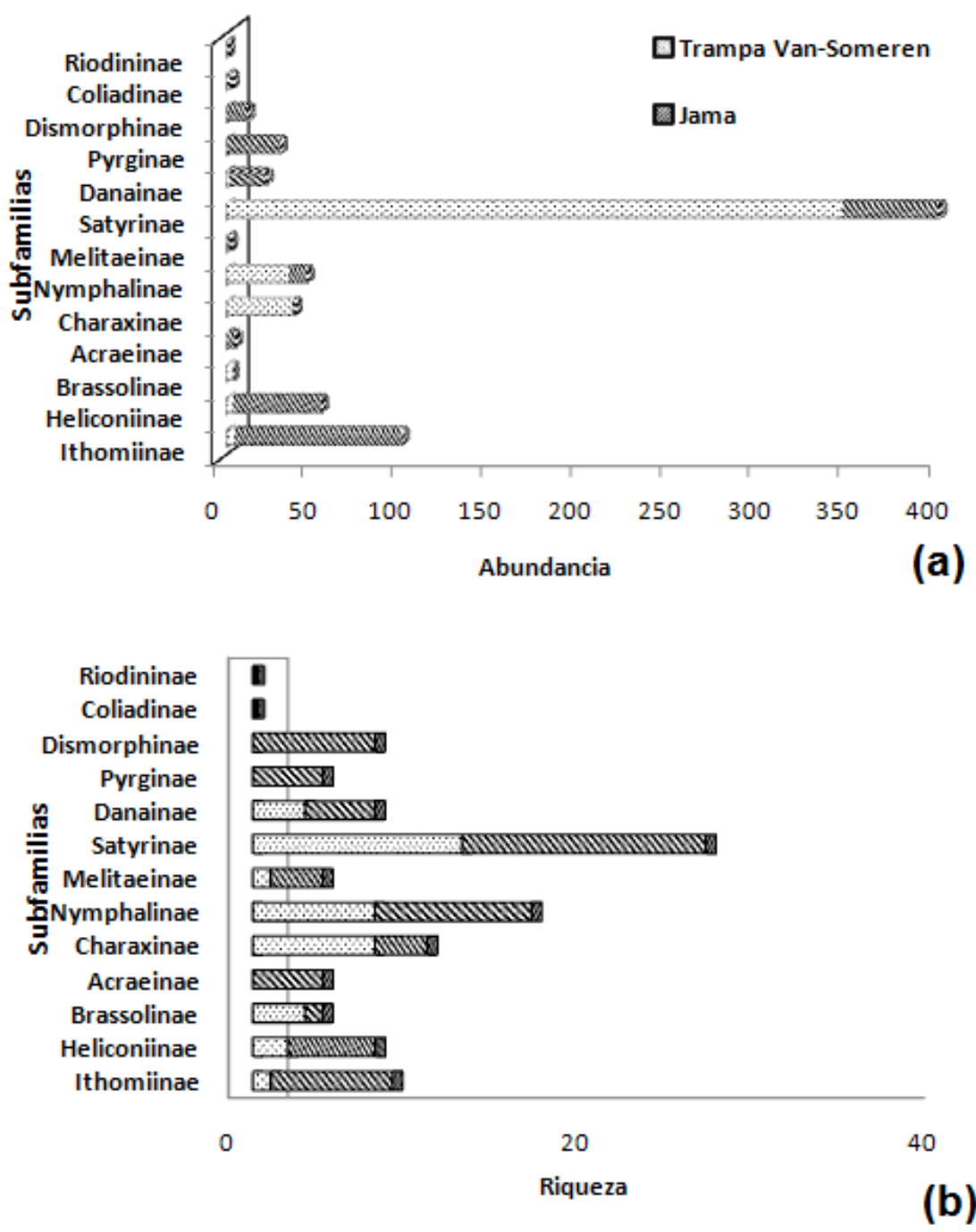

Figura 10. Riqueza y abundancia de mariposas colectadas con los dos métodos de muestreo en la reserva natural "Raíces de Vida”, colegio Carmen de Quintana (Cajibío, Cauca).

De las 80 especies encontradas, 67 fueron colectadas en el transecto uno donde se incluyen 10 especies indicadoras de áreas intervenidas y tan solo cinco especies indicadoras de conservación; asimismo, en el transecto dos se presentaron 45 especies, 10 de áreas intervenidas y cuatro de áreas conservadas, y finalmente en el transecto tres 27 especies, seis de áreas perturbadas y tres de conservación. En la Figura 11 se muestra la riqueza de especies por transecto y la distribución de especies compartidas entre transectos. Todas las subfamilias muestreadas en el estudio poseen al menos una especie en cada transecto. 


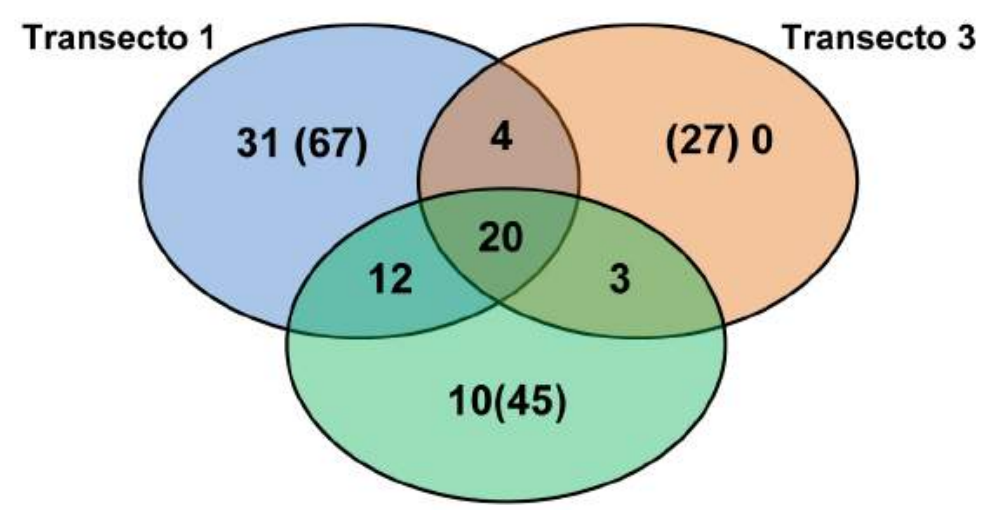

Transecto 2

Figura 11. Riqueza total de especies por transecto ( ) y compartidas entre transectos dentro de la reserva natural "Raíces de Vida”, colegio Carmen de Quintana (Cajibío, Cauca).

De acuerdo con los datos obtenidos en cuanto a riqueza, abundancia, composición de los lepidópteros y variables habitacionales, además de todas las observaciones realizadas y con los datos obtenidos por RAMÍREZ et al. (2006) sobre la caracterización florística de la reserva, se puede afirmar que el fragmento de bosque se encuentra en un gradiente sucesional y al mismo tiempo en diferentes grados de ese estado sucesional, de esta manera para establecer qué tanto pueden estar afectando las diferentes actividades que se realizan no solo en el interior del relicto sino también en la matriz aledaña, es necesario complementar el análisis con una evaluación ecológica rápida que permita identificar las actividades que más están impactando, no solo a la comunidad de lepidópteros sino además generando un desequilibrio general del sistema. Esta interpretación servirá como herramienta para proponer estrategias de manejo y conservación para la reserva.

\section{Evaluación ecológica rápida}

En el municipio de Cajibío se desarrollan diversas actividades como el aumento de las áreas productivas, que impactan negativamente el ecosistema de bosque. Las tensiones se caracterizan por la eliminación de cobertura vegetal nativa para el establecimiento de monocultivos, acentuando los procesos de fragmentación y reducción de las áreas boscosas, causando desplazamiento y pérdida de la fauna de la zona.

En la Tabla 2 se presentan los componentes identificados que se han visto afectados directamente por las actividades desarrolladas en el ecosistema, las cuales son representativas para la determinación de estrategias que mitiguen su impacto, de este modo se confrontan las actividades con los efectos tensionantes, en este caso las actividades de uso del suelo. Se determina que dentro de los componentes abiótico y biótico, los subcomponentes más afectados son la cobertura vegetal, la fauna y el suelo por la práctica de actividades como la ganadería, monocultivos, la 
quema y la tala, las cuales se evidenciaron como los impactos significativamente adversos y adversos.

Las actividades mencionadas tensionan e impactan el ecosistema de manera conjunta, generando pérdida de la vegetación y, por ende, la reducción de las comunidades faunísticas asociadas a este tipo de ecosistemas productivos, además de aumentar la exposición lumínica debido a la remoción indiscriminada de cobertura vegetal (CONCHA, 2008), por lo cual se afecta todo tipo de organismos, incluyendo las mariposas que poseen una alta sensibilidad a cambios del ambiente y dependen de la estabilidad de la estructura del ecosistema.

Tabla 2. Matriz de FEARO para el bosque de la reserva.

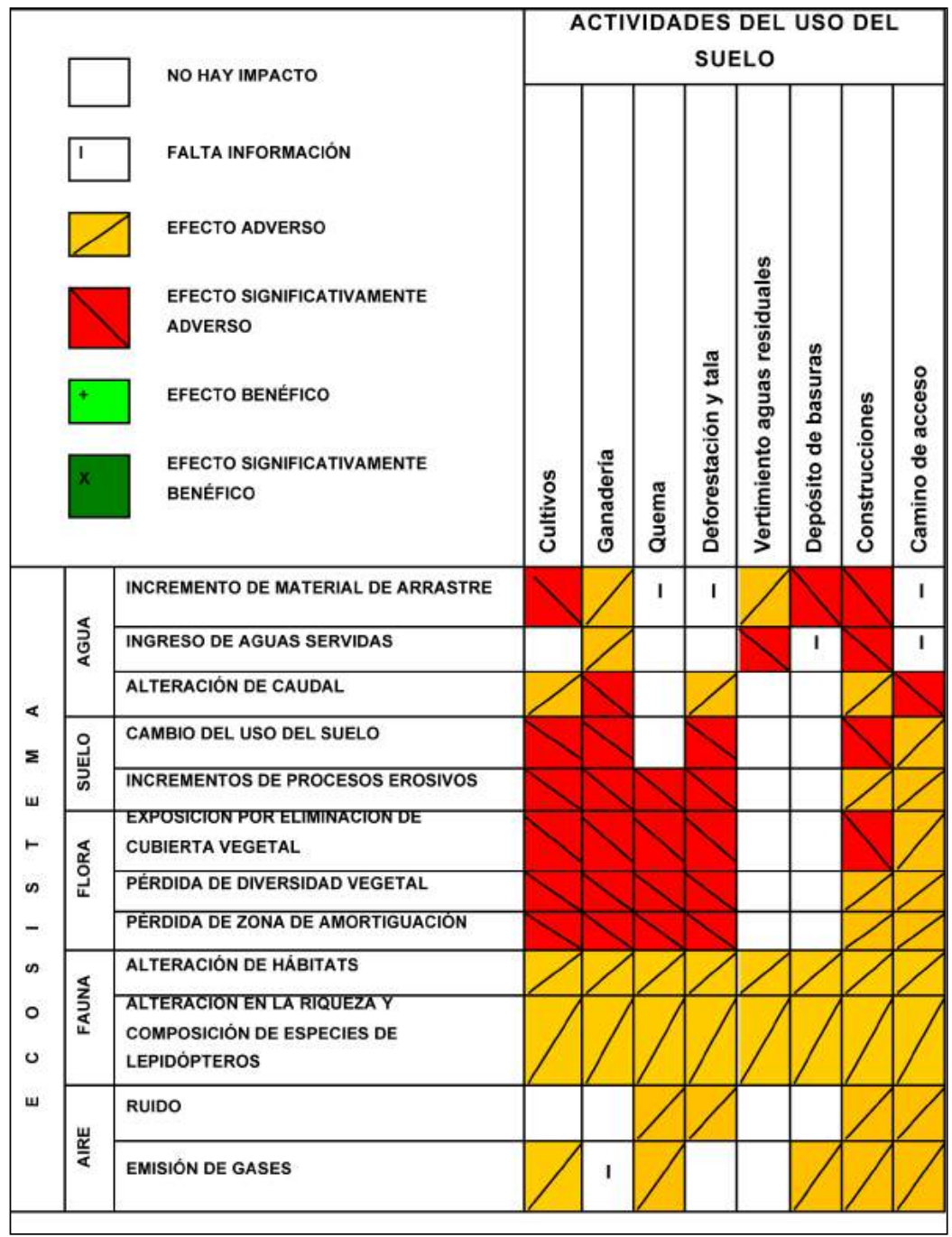


Fichas de manejo ambiental

Para la formulación de la ficha de manejo ambiental, se tuvieron en cuenta los resultados obtenidos en la matriz de FEARO. A continuación se relacionan las actividades que mayor impacto tienen sobre el bosque de la reserva, esto con el fin de generar alternativas mitigadoras y crear espacios de conservación y de educación ambiental en la comunidad de Cajibío. Se identificaron para este ecosistema las siguientes actividades tensionadoras: cultivo y ganadería (Tabla 3).

La identificación de las diferentes actividades antrópicas que se realizan en la matriz y en el bosque de la reserva natural "Raíces de Vida", como la ganadería, cultivos agrícolas y forestales y la tala, actúan de forma drástica fragmentando y transformando los sistemas naturales, actividades que definitivamente modifican la composición faunística y en este caso la comunidad de especies de lepidópteros. Los resultados de esta investigación acerca de la especificidad de las mariposas diurnas sugieren que, de alguna manera, ellas responden a los cambios en las coberturas vegetales, pues en el interior de la reserva se pueden generar microhábitats que interfieran en la dinámica natural de los lepidópteros. En consecuencia, los resultados manifestaron una representación de especies indicadoras de áreas perturbadas como son: Anartia amathea, Euptychia hermes, Phoebis sennae, Actinote equatoria, Adelpha alala, Heliconius clysonimus, Diaethria marchalii, Eurema venusta, Eurema xanthochlora y Oxeoschistus simplex.

\section{CONCLUSIONES}

Nymphalidae fue la familia que mayor número de individuos y especies aportó a la diversidad de mariposas diurnas de la reserva, seguida de Pieridae y Lycaenidae. La subfamilia más representativa en cuanto a abundancia y riqueza fue Satyrinae con 435 individuos y 15 especies, y se caracteriza por preferir áreas abiertas.

La reserva natural "Raíces de Vida" es una importante área a seguir conservando, pues no solo es el pulmón del municipio de Cajibío, sino que además alberga una alta biodiversidad; 14 de las especies de mariposas registradas son indicadoras de áreas perturbadas y a su vez tan solo cinco del estado de conservación del bosque. $\mathrm{Al}$ analizar los coeficientes de correlación entre la abundancia y riqueza con las variables habitacionales, se observa un comportamiento inversamente proporcional, lo que sugiere que el bosque está en un proceso sucesional temprano y que las especies presentes prefieren zonas o espacios abiertos.

La evaluación ecológica rápida identificó para la reserva que las actividades más tensionadoras fueron los monocultivos, la ganadería y la extracción de madera que los habitantes aledaños realizan sin autorización, estas actividades están influyendo sobre la comunidad de lepidópteros, lo cual sugiere empezar a realizar todo un trabajo de educación ambiental con los habitantes. 
Tabla 3. Ficha de manejo ambiental para el bosque de la reserva.

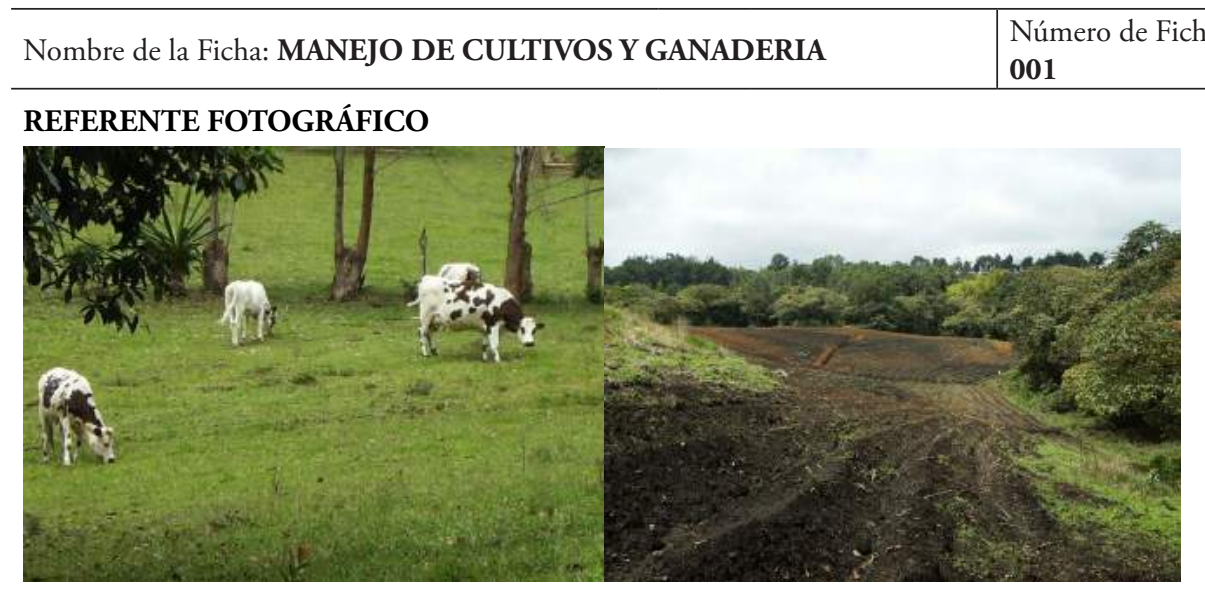

Objetivo: Orientar a la comunidad en el manejo adecuado de las áreas ganaderas como zonas de conservación y aprovechamiento económico.

\begin{tabular}{l|l}
\hline $\begin{array}{l}\text { Actividades: Expansión de áreas productivas, como cul- } \\
\text { tivos de yuca, café y ganadería }\end{array}$ & $\begin{array}{l}\text { Componente Afectado: biótico. } \\
\text { Subcomponente: agua, suelo, flora } \\
\text { y fauna. }\end{array}$ \\
\hline
\end{tabular}

\section{DESCRIPCIÓN DE LA ACTIVIDAD}

Estas actividades se establecen para generar ingresos y cubrir las necesidades básicas como la alimentación, vivienda y estudio a los habitantes de la comunidad del municipio de Cajibío. Aledaño al bosque se ve notoriamente el uso que se le está dando al suelo, que afecta no solo a éste, sino también a otros componentes del ecosistema como la vegetación y fuentes de agua, que perturban indirectamente la comunidad de lepidópteros. Esta actividad se encuentra representada por una gran extensión de siembra de yuca, algunos pequeños cultivos de café y áreas destinadas a la ganadería, perturbando considerablemente la vegetación y fauna asociada al relicto de bosque.

\section{EFECTOS ADVERSOS}

1. Pérdida de la calidad del suelo.

2. Cambios y/o alteración de la riqueza y abundancia de las comunidades de lepidópteros.

3. Pérdida de cobertura arbórea.

6. Pérdida y solapamiento de nichos.

7. Disminución de las áreas de bosque.

8. Incremento de material de arrastre y procesos erosivos.

9. Alteración del caudal.

\section{ACCIONES A DESARROLLAR}

1.Capacitación ambiental y gestión local de riesgos.

2.Mejoramiento del paisaje con actividades de revegetalización:

- Cobertura arbórea nativa.

- Corredores ornamentales nativos.

3. Capacitación de:

- Agricultura orgánica.

- Alternativas de mejoramiento agrícola.

\section{SEGUIMIENTO Y MONITOREO}

Los planes de manejo ambiental deben ser participativos, de esta manera, en el momento en que las acciones a desarrollar completen su fase, la comunidad deberá realizar el seguimiento y monitoreo de sus actividades de mejoramiento, uso y manejo adecuado de los recursos naturales. 


\section{AGRADECIMIENTOS}

Los autores expresan sus agradecimientos a la Institución Carmen de Quintana, a Doña María, Don Miguel y Biani, a la Universidad del Cauca, al Grupo de Estudios Ambientales (GEA), y a los evaluadores anónimos por sus sugerencias.

\section{BIBLIOGRAFÍA}

ÁLVAREZ, J., 1993.- Inventario de Mariposas (Lepidoptera, Rhopalocera) con anotaciones ecológicas, para dos zonas en el departamento de Risaralda Colombia. UNAL, Santa fe de Bogotá.

AMAT, G., FERNÁNDEZ, F. \& ANDRADE, G., 1999.- Un vistazo actual a la taxonomía de insectos en Colombia (Coleoptera, Himenóptera y Lepidóptera). Insectos de Colombia, 1: 14-33.

ANDRADE, G., 1993a.- Una nueva especie de “Antirrea” (Lepidoptera: Nymphalidae: Morphinae), de la cordillera occidental de Colombia. Revista Academia Colombiana de Ciencias, 18 (71): 555-558.

, 1993b.- Las mariposas del Parque Regional Natural Ucumarí: Distribución local y estacional de Rhopalocera (en) RANGEL, O. (ed.) Ucumarí, un caso típico de la diversidad biótica andina. Carder, ICN, Bogotá, Colombia.

1994.- Estudio de conservación y biodiversidad de las mariposas en dos zonas de bosque primario y secundario en Colombia. Revista de Lepidopterología SHILAP, 22 (86).

ANDRADE, G., 2002.- Biodiversidad de las mariposas (lepidóptera: Rhopalocera) de Colombia. Instituto de Ciencias Naturales, Universidad Nacional de Colombia, Bogotá, Colombia.

ANDRADE, G. \& AMAT, G., 1996.- Estudio regional de las mariposas altoandinas en la cordillera Oriental de Colombia. Insectos de Colombia, 1: 149-180.

ARIAS, J. \& HUERTAS, B., 2001.- Mariposas diurnas de la serranía de los Churumbelos, Cauca. Distribución altitudinal y diversidad de especies. (Lepidóptera Rhopalocera: Papilionoidea). Revista Colombiana de Entomología, 27 (3-4): 169-176.

BROWN, K.S, 1997.- Diversity, disturbance, and sustainable use of Neotropical forests: Insects as indicators for conservation monitoring. Journal. Insect. Conserv. 1: 25-42.

BROWN, K. \& FREITAS, A., 2002.- Butterfly communities of urban forest fragments in Campinas, Sao Paulo, Brazil: structure, instability, environmental correlates, and conservation. Journal of Insect Conservation, 6: 217-231.

COLWELL, R., 1998.- User's guide to the richness estimator program, EstimateS. Versión 5.1. Published at http://viceroy.eeb.uconn.edu/EstimateS.

CONCHA, C., 2008.- Evaluación ecológica rápida de tres ecosistemas estimando el ensamble de la comunidad de coleópteros coprófagos (col: scarabaeinae), Vereda Clarete, Popayán, Cauca. Tesis, Universidad del Cauca, Departamento de biología, Popayán.

FAGUA, G., 1996.- Comunidad de mariposas y artropofauna asociada al suelo de tres tipos de vegetación de la serranía de Taraira (Vaupés, Colombia). Una prueba del uso de mariposas como bioindicadores. Revista Colombiana de Entomología, 22 (3): 143-151.

FIGUEROA, A., CONTRERAS R. \& SÁNCHEZ, J., 1998.- Evaluación de Impacto Ambiental. Un Instrumento para el Desarrollo. Centro de Estudios Ambientales para el Desarrollo Regional (CEADES), Corporación Universitaria Autónoma de Occidente, Cali. Colombia, Toro Corredor Editores Ltda. 87-89.

FRAIJA, N. \& FAJARDO, G., 2005.- Caracterización de la fauna del orden Lepidóptera (Rhopalocera) en cinco diferentes localidades de los Llanos Orientales colombianos. Acta Biológica Colombiana, 11 (1): 55-68.

GARCÍA-PÉREZ, J., OSPINA-LÓPEZ, L.A., VILLA-NAVARRO, F.A \& REINOSO-FLÓREZ, G., 2007.- Diversidad y distribución de mariposas Satyrinae (Lepidoptera: Nymphalidae) en la cuenca del río Coello, Colombia. Rev. Biol. Trop., 55 (2): 645-653.

GÓMEZ, W., 2006.- Diversidad de la comunidad de mariposas diurnas (Lepidoptera: Rhopalocera) en la Reserva Natural Río Nambí. Nariño. Tesis Universidad del Quindío, Facultad de Ciencias Naturales Exactas y de la Educación, Armenia.

HARDY, P. \& DENNIS, R., 1999.- The impact of urban development on butterflies within a city region. Biodiversity and Conservation, 8: 1261-1279.

JIMÉNEZ, A., CANO, J. \& MUNGUIRA, M., 2004.- Patrones de diversidad de la fauna de mariposas del Parque Nacional de Cabañeros y su entorno. Ciudad Real, España. (Lepidoptera, Papilionoidea, Hesperioidea). Animal Biodiversity and Conservation, 27(2): 15.

KREMEN, C., 1994.- Ecological monitoring: a vital need for integrated conservation and development programs in the tropic. Conservation Biology, (2): 388-397.

KREMEN, C., COLWELL, R., ERWIN, L., MURPHY, D., NOSS D. \& SANJAYAN, M., 1993.-Terrestrial arthropod assemblage: Their use in conservation planning. Conservation Biology, (4): 796-808.

LONGINO, J., 1994.- How to measure arthropod diversity in a tropical rainforest. Biology International, (28): 3-13. 
PALACIOS, M., 2006.- Estructura y composición de la comunidad de Lepidópteros Rhopalocera en un gradiente altitudinal en la Reserva Natural el Pangan, Nariño. Colombia: Tesis, Fundación Universitaria de Popayán, Facultad de Ciencias Naturales. Popayán.

POLLARD, E. \& YATES, T., 1996.- Monitoring butterflies for ecology and conservation. Chapman \& Hall, Londres.

PRIETO, A. \& CONSTANTINO L., 1996.- Abundancia, distribución y diversidad de mariposas (LepidópteraRhopalocera) en el Río Tatabro (Buenaventura - Colombia). Bol Mus Ent Univ Valle, 4(2): 11-18.

RAMÍREZ, L., 2004.- Diversidad de mariposas en diferentes zonas verdes de Cali. Colombia: Tesis, Universidad del Valle, Facultad de Ciencias, Santiago de Cali.

RAMÍREZ, B., OTÁLORA, N. \& FERNÁNDEZ, Y., 2006.- Caracterización florística de la Reserva Natural "Raíces de Vida" colegio Carmen de Quintana, Municipio de Cajibío, Cauca. Colombia. Universidad del Cauca, Facultad de Ciencias Naturales, Exactas y de la Educación, Popayán.

RODRÍGUEZ, C. \& RAMÍREZ, C., 2004.- Mariposas (Lepidóptera, Rhopalocera) del departamento del Quindío. Revista de Investigaciones Universidad del Quindío, 14: 17-30.

RYDON, A., 1964.- Notes on the use of butterfly traps in East Africa. J. of the Lepidopteris' Society, 51-58.

SALAZAR, J., 1995.- Lista preliminar de las mariposas diurnas (Lep. Rophalocera) que habitan en el departamento del Putumayo. Notas sobre su distribución en la zona Andina. Colombia Amazónica, 8: 1-69.

TOBAR, D., RANGEL, O. \& ANDRADE, G., 2002.- Diversidad de mariposas (Lepidoptera: Rhopalocera) en la parte alta de la cuenca del río El Roble (Quindío). Instituto Alexander Von Humboldt - Instituto de Ciencias Naturales, Universidad Nacional de Colombia, Bogotá.

VÉLEZ, J. \& SALAZAR, J., 1991.- Mariposas de Colombia. Villegas Editores, Bogotá.

WARREN, M.S., 1985.- The influence of shade on butterfly numbers in woodland rides, with special reference to the Wood White Leptidea sinapis. Biological Conservation, 33: 147-164. 